\title{
Al-Turas
}

website : bit.ly/buletinalturas

\section{Bahasa Arab untuk Tujuan Khusus di Indonesia dan Malaysia: Tinjauan Normatif dan Empiris}

\author{
Mauidlotun Nisa \\ Universitas Islam Negeri Syarif Hidayatullah \\ Jakarta, Indonesia \\ mauidlotun.nisa@uinjkt.ac.id \\ Syamsul Arifin \\ Universitas Islam Negeri Syarif Hidayatullah \\ Jakarta, Indonesia \\ syamsul.arifin@uinjkt.ac.id
}

\begin{abstract}
This article aims to uncover the paradigm of Arabic for special purposes in Indonesia and Malaysia through formal and informal institutions. This qualitative field study makes use of primary data obtained from curriculum documents and interviews with teachers and authorities; and the secondary data taken from the result of relevant literature studies. The collected data were analyzed using an approach adapted from the ESP concept introduced by Dudley-Evans. The study shows that Arabic for special purposes both in Indonesia and in Malaysia was practiced by several educational and non-educational institutions. The teaching of Arabic language for academic purposes at STFI Sadra Jakarta uses a strategy for comprehending the text and other literatures on Quran and its interpretation. Arabic for vocational purposes at PT. Mutiara Bahari Alamria, Bekasi uses an oral communication strategy that focuses on everyday language and vocabulary. Arabic for religious purposes at LBIQ Jakarta is directed mainly at the acquisition of Quranic Arabic. While, the teaching of Arabic at IIUM (International Islamic University Malaysia) is directed at the mastery of academic and religious purposes to meet the special needs, such as Business, Tourism, Medical, Hajj and Umrah; and for ordinary people to understand the Quran and worship. The teaching of Arabic for academic purposes in Malaysia is also done by Akademi Pengajian Islam, Universiti Malaya (APIUM) with an emphasis on understanding Sharia and Fiqh in Arabic. Arabic for vocational purposes at UPNM-Kuala Lumpur is carried out with strategies covering Arabic language competition activities such as Arabic debate, Arabic speech, and apprenticeship activities in native Arabic speakers' families.
\end{abstract}

Keywords: Arabic for special purposes; Indonesian; Malaysian; normative, empirical

Doi: $10.15408 /$ bat.v26i1.13303 


\section{Abstrak}

Artikel ini bertujuan untuk mengungkap paradigma bahasa Arab untuk tujuan khusus di Indonesia dan Malaysia melalui lembaga-lembaga formal dan informal. Penelitian ini merupakan penelitian kualitatif lapangan yang data primernya diperoleh dari dokumen kurikulum dan wawancara dengan guru dan pihak yang berwewenang; data sekunder diperoleh dari hasil kajian literatur yang relevan. Data penelitian dianalisis dengan menggunakan pendekatan yang diadaptasi konsep ESP yang diperkenalkan oleh Dudley-Evans. Hasil penelitian memperlihatkan Bahasa Arab untuk tujuan khusus baik di Indonesia maupun di Malaysia dipraktikkan oleh beberapa lembaga pendidikan dan nonkependidikan. Bahasa arab untuk tujuan akdemik di STFI Sadra Jakarta menggunakan strategi pemahaman teks dan literatur Alquran dan tafsir. Bahasa Arab untuk tujuan pekerjaan di PT. Mutiara Bahari Alamria, Bekasi menggunakan strategi komunikasi secara lisan yang berfokus pada kosakata. Bahasa Arab untuk tujuan agama di LBIQ Jakarta diarahkan pada bahasa Arab Qurani. Bahasa Arab di IIUM (International Islamic University Malaysia) diarahkan pada tujuan akademik dan agama untuk memenuhi kebutuhan bidang khusus seperti Bisnis, Pariwisata, Medis, haji dan umrah; dan untuk memahami Alquran dan ibadah bagi orang awam. Bahasa Arab untuk tujuan akademik di Malaysia juga dipraktikkan oleh Akademi Pengajian Islam, Universiti Malaya (APIUM) dengan penekanan pada pemahaman Syariah dan Fiqih berbahasa Arab. Bahasa Arab untuk tujuan pekerjaan di UPNM-Kuala Lumpur dilakukan dengan strategi kegiatan kompetisi bahasa Arab seperti debat bahasa Arab, pidato bahasa Arab, dan kegiatan magang di keluarga penutur asli bahasa Arab.

Kata Kunci: Bahasa Arab untuk tujuan khusus; Indonesia; Malaysia; normatif; empiris

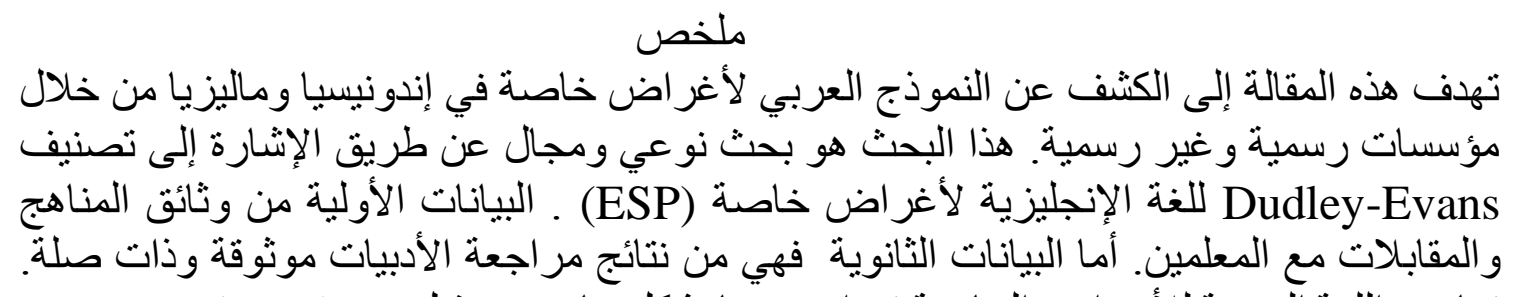

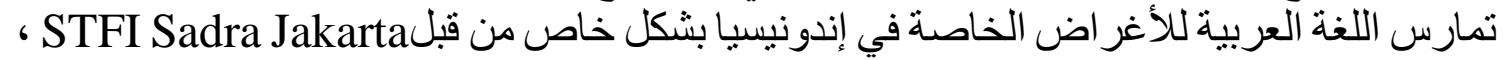
جاكرنا. PT. Mutiara Bahari Alamria بينما تمارس في ماليزيا من قبل IIUM (الجامعة الإسلامية الدولية في ماليزيا) ، و أكاديمية الدر اسات

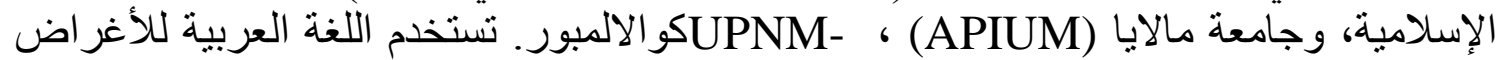

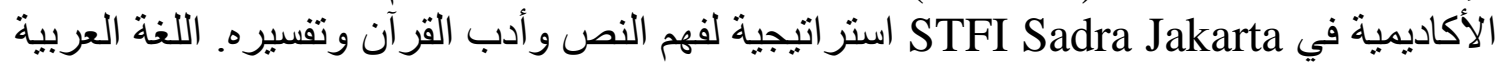
لأغر اض العمل في حزب العمال Mutiara Bahari Alamria Jatirangon Jatisampurna

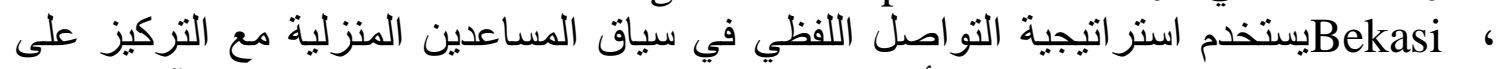

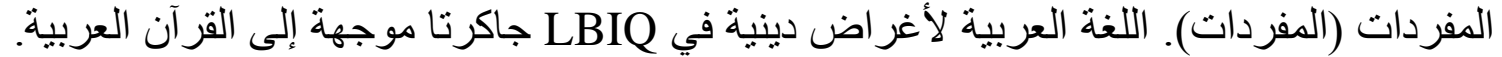

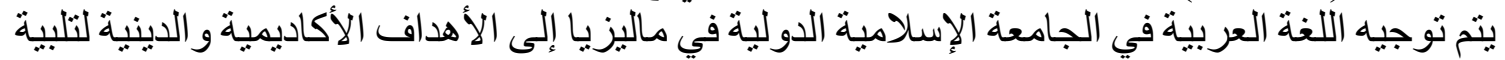

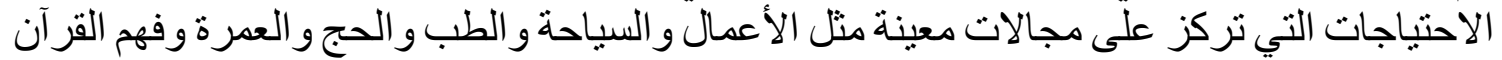

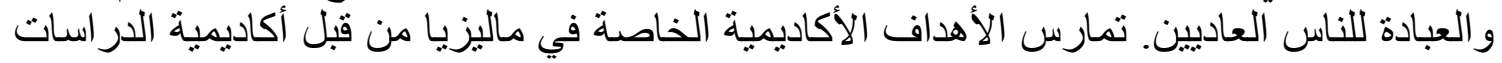

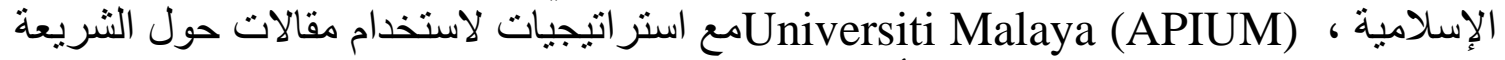

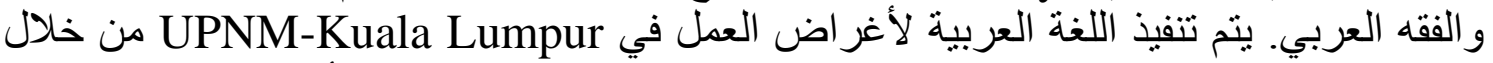

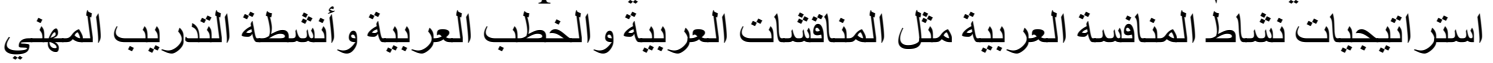

$$
\text { في عائلات الناطقين باللغة العربية. }
$$

$$
\text { الكلمات المفتاحية: العربية لأغر اض خاصةة، إندونيسية، ماليزية، معيارية، تجريبية }
$$




\section{PENDAHULUAN}

Era modern meniscayakan aktivitas kebahasaan yang sesuai dengan kebutuhan riil masyarakat. Meski muncul banyak teori-teori bahasa modern yang mencabut sampai akarnya teori-teori sebelumnya, seperti Comsky dengan teori behaviorisme yang dikalahkan oleh teori bahasa yang berpusat pada kebutuhan pemelajar dan tujuannya yang spesifik dalam mempelajari bahasa, begitu juga dengan metode pembelajaran (Richards, 2008, p. 25); Al-Khulli, 1986; Tu'aimah, 1989). Metamorfosis ini mengarahkan kita pada pembelajaran bahasa untuk tujuan khusus yang mengacu pada tujuan pemelajar dan semua kebutuhannya (Madkur \& Huraidi, 2006, p. 115). Jadi, perancangan silabus dan kurikulum pembelajaran bahasa untuk tujuan khusus diarahkan pada kebutuhan pemelajar melalui analisis kebutuhan (need analysis) (Mahmud, 1983, p. 115). Bahkan Fadel Abdallah mengatakan bahwa pembelajaran bahasa Arab untuk saat ini lebih diarahkan pada tujuan khusus baik untuk tujuan akademik maupun untuk tujuan pekerjaan (Abdallah, 2006). Pembelajaran bahasa Arab untuk tujuan khusus diadopsi dari konsep ESP (English for Specific Purposes) yang telah lebih dulu populer. Konsep ESP telah banyak digunakan di berbagai pembelajaran bahasa Inggris di berbagai dunia.

Konsep LSP (Language for Specific Purposes) dimulai dan diadopsi dari ESP (English for Specific Purposes) karena pada kenyataannya ESP sangat mendominasi literatur dan sangat luas distribusinya terhadap bahasa dunia. Salah satu buktinya adalah pembagian LSP sendiri mengadopsi dari kategori ESP menurut Robinson. LSP terbagi menjadi dua bagian yaitu LOP (Language for Occupational Purposes) bahasa untuk tujuan pekerjaan dan LAP (Language for Academic Purposes) bahasa untuk tujuan akademik. LOP sendiri juga terdiri dari dua kategori yaitu bahasa untuk tujuan profesi (Language for Professional Purposes) dan bahasa untuk tujuan pendidikan kejuruan (Language for Vocational Purposes). Sedangkan LAP terdiri dari dua kategori yaitu bahasa untuk ilmu pengetahuan dan teknologi (Language for Science and Technology) dan LAP yang selain LST (Tuesday, 2011, pp. 53-59; Wahab, 2007, pp. 1-18).

Pembelajaran Bahasa Arab di Barat mulai muncul di Inggris dengan istilah TAFL (Teaching Arabic as a Foreign Language). Pada dasarnya TAFL sudah ada sejak 20 tahun yang lalu dan bidang ini di bawah langsung dalam penelitian pemerolehan bahasa kedua.(Amayirah, 1996, p. 372; Belnap, 1992, p. 80; Wahab, 2007, pp. 61-76) Orang Barat membagi bahasa Arab menjadi bahasa Arab klasik, standar modern, dan percakapan. Akan tetapi pada kenyataannya bahasa Arab standar modern (Modern Standar Arabic) disingkat MSA yang banyak digunakan. Orang Barat berusaha mengefesienkan bidang pengajaran bahasa Arab (Arsyad, 2003, pp. 136-137).

Seperti contoh di McGill University pada program Islamic Studies, mahasiswa diwajibkan mengikuti pembelajaran bahasa Arab untuk tujuan akademik. Artinya, ada tuntunan bagi mahasiswa untuk mampu memahami dan membaca teks Arab gundul seperti buku karya Taha Husain. Dari pembelajaran yang telah dilakukan, pengajaran bahasa Arab yang ada mampu membawa mahasiswa untuk bisa membaca kitab gundul dalam waktu yang cukup singkat dengan hanya 2 tahun dan dalam posisi kemampuannya nol (Arsyad, 2003, p. 153). Artinya, diduga kuat pendidikan bahasa Arab yang seperti ini, yaitu dengan diorientasikan untuk tujuan khusus sesuai dengan kebutuhan peserta didik akan lebih efektif dan tepat guna sesuai dengan kebutuhan riil. Selain di McGiil university, pembelajaran bahasa Arab di Leipzig Universuty-Jerman pada kajian orintalisme juga sangat berkembang dan sukses besar. Diduga kuat, kesuksesan tersebut disebabkan adanya tujuan pembelajaran yang fokus yaitu pemahaman teks Alquran dan 
literatur Islam. Artinya, jika bahasa Arab dipelajari sesuai kebutuhan dengan tujuan yang jelas, maka pembelajarannya akan lebih efektif.

Dari fakta di atas, dapat diketahui bahwa pendidikan bahasa Arab yang diselenggarakan dengan menggunakan pendekatan untuk tujuan khusus sangat penting dalam rangka mewujudkan bahasa Arab yang berprospek praktis dan profesional. Artinya, ketika pembelajaran bahasa Arab dikemas dengan baik sesuai dengan kebutuhan pelajar dan masyarakat, maka secara otomotis sebenarnya ada faktor motivasi dari pelajar itu sendiri. Jika pelajar sudah memiliki motivasi dalam mempelajari bahasa Arab, maka hasilnya akan sangat memuaskan.

Penelitian secara umum juga sangat berbeda dengan sebelumnya. Meski tidak sedikit penelitian yang membahas masalah ini, akan tetapi penelitian ini tidak sekedar memetakan institusi baik formal maupun non-formal yang menyelenggarakan kursus bahasa Arab untuk tujuan khusus. Penelitian ini lebih mencoba membuktikan bagaimana proses penyelenggaraannya apakah sesuai dengan kriteria teoretis dalam kasus Arabic for Specific Puposes (ASP) yang diadopsi dari ESP. Tidak hanya itu, penelitian juga dengan berani ingin mengkomparasikan kasus ASP antara Indonesia dan Malaysia. Dimana Malaysia secara kultural selevel dengan Indonesia, artinya posisi bahasa Arab di Indonesia dan Malaysia berada pada level yang sama, yaitu bahasa Asing. Hal ini menjadi penting ketika sebuah fakta dari berbagai penelitian empiris mengatakan bahwa pendidikan bahasa Arab khsusunya ASP di Malaysia lebih menggeliat di berbagai sektor pemerintahan, baik bidang ekonomi dan pariwisata dari pada di Indonesia.

\section{METODE}

Tulisan ini merupakan penelitian kualitatif yang berbasis penelitian lapangan dengan menggunakan klasifikasi English for Specific Purposes oleh Dudley-Evans. Penelitian ini dibatasi pada lembaga yang menyelenggarakan pembelajaran bahasa Arab di Jakarta dan Kuala Lumpur sebagai ibu kota Indonesia dan Malaysia.

Sumber primer penelitian ini adalah dokumen kurikulum dan informasi tentang pembalajaran bahasa Arab untuk tujuan khusus di Pusat Bahasa, Universiti Pertahanan Nasional Malaysia yang menyelenggarakan pembelajaran bahasa Arab untuk KAGAT dan Islamic International University of Malaya (IIUM). Di Indonesia, STFI Sadra Jakarta dan PT. Mutiara Alamria Jatirangon Jatisampurna Bekasi Jawa Barat untuk para CTKI (Calon Tenaga Kerja Indonesia) ke Timur Tengah, LBIQ (Lembaga Bahasa dan Ilmu AlQuran). Adapun sumber sekunder penelitian ini adalah literatur otoritatif yang mengkaji konsep bahasa Arab untuk tujuan khusus yang mengacu pada konsep ESP, baik berupa artikel jurnal, dan surat kabar. Karena penelitian ini termasuk penelitian kepustakaan dan lapangan, teknik pengumpulan datanya menggunakan metode triangulation,

Mengacu pada sumber data yang telah disebutkan, maka teknik pengumpulan data dalam penelitian ini adalah survei, observasi, wawancara, dan melakukan review hasil penelitian yang telah menghasilkan temuan mengenai pembelajaran bahasa Arab untuk tujuan khusus di lembaga atau institusi tertentu. Wawancara telah dilakukan terhadap pimpinan Pusat Bahasa, Universiti Pertahanan Nasional Malaysia yang menyelenggarakan pembelajaran bahasa Arab untuk KAGAT, Najjah Salwa Abd. Razak dan Kaprodi Bahasa dan Sastra Arab Islamic International University of Malaya (IIUM), Muhammad Sabri Sahrir. Di Indonesia, wawancara dilakukan dengan ketua Program Bahasa Arab STFI Sadra Jakarta, Nurdin Merza Wijaya. Wawancara dengan masyarakat sekitar PT. Mutiara Alamria Jatirangon Jatisampurna Bekasi Jawa Barat, dan dengan 
pengajar bahasa Arab di LBIQ, Ikhwan Azizi. Data yang ada dianalisis dengan menggunakan teknik analisis data deskriptif.

\section{TEMUAN DAN PEMBAHASAN}

\section{Perkembangan Kajian Bahasa Arab untuk Tujuan Khusus di Indonesia dan Malaysia}

Bahasa Arab untuk tujuan khusus di Malaysia telah menggeliat berkembang lebih pesat jika dibanding di Indonesia. Kebijakan pemerintah Malaysia di bawah Perdana Menteri Abdullah Badawi mewajibkan semua lembaga pendidikan (Islam, Kristen, Budha, Konghucu, dsb.) untuk mengajarkan bahasa Arab pada tingkat dasar dan menengah, karena pemerintah menghendaki para lulusan lembaga pendidikannya itu mempunyai daya saing dan keterampilan yang sesuai dengan tuntutal masyarakat global (Wahab, 2007, pp. 1-18).

Hal ini dibuktikan dengan adanya banyak penelitian yang dilakukan oleh para akademisi dalam mengkaji praktik pendidikan bahasa Arab untuk tujuan khusus yang ada di Malaysia, bahkan sudah sampai pada tataran merancang dan mendesain kurikulumnya. Seperti Abdurrahman Shik dengan tulisannya berjudul Ta'lim al-Lughah al- 'Arabiyyah li Aghradlin Khasshah fi Maliziya menyebutkan semua jenis penelitian yang sudah dilakukan di Malaysia mengenai bahasa Arab untuk tujuan khusus, mulai dari tahun 19882009 (Chik, 1988). Kajian yang membahas bahasa Arab untuk tujuan khusus di antaranya adalah Teaching Arabic for Specific Purposes (ASP) with Special Reference to Teaching Reading Skills at the International Islamic karya Abdul Rahman Chik. Ia adalah peneliti pertama yang meneliti tentang metode pembelajaran bahasa Arab untuk tujuan khusus di Malaysia sesuai dengan kebutuhan pemelajar, seperti bahasa Arab untuk mahasiswa fakultas hukum dan ekonomi di Universitas Islam Malaysia. Ta'lim al-'Arabiyyah li Aghradlin 'Amaliyyah: Bina' Wihdat Dirasiyyah li Ta'lim al-'Arabiyyah li AlMutakhassisin fi al-Fiqh karya Nadwah Bint Dawud tahun 1988, Ta'lim al-Lughah al'Arabiyyah li Aghrad\}in Khasshah, Bina' Wihdat Dirasiyyah li Thullab al-Takhasshush fi al-'Aqidah karya Muhammad 'Abd al-Kalam Azad. Kedua penelitian itu adalah perancangan program pembelajaran bahasa Arab untuk ilmu keislaman yaitu fiqih dan Aqidah. Pengajaran dan Pembelajaran Bahasa Arab Untuk Tujuan-tujuan Khusus: Analisis Keperluan di Malaysia karya Lazim bin Umar (Umar 1999). Penelitian ini menghasilkan model pembelajaran bahasa Arab untuk para pegawai kebudayaan di pemerintahan Malaysia seperti Kementerian Luar Negeri, departemen pariwisata di Kementerian Budaya, Seni, dan Pariwisata, dan Departemen di bidang Haji. Tasmim Wihdat Dirasiyyah li al-Hujjaj wa al-Mu'tamirin al-Maliziyyin fi Ta'lim al-Lughah al'Arabiyyah li Aghradlin Khasshah karya 'Abd al-Halim bin Shalih tahun 2005, Ta'lim al-'Arabiyyah li al-Aghradlin al-Diblumasi karya Islam Yasri tahun 2008, Ta'lim al'Arabiyyah li Aghradlin Khasshah: Durus li al-Mutakhasshishin fi Majal al-Iqtishad karya Najmiyyah Dawud tahun 2009, kedua penelitian ini menghasilkan model pembelajaran bahasa Arab untuk para diplomat dan ekonomi (Chik, 1988).

Berbeda dengan Malaysia, kurikulum dan model pembelajaran bahasa Arab yang dikembangkan di Indonesia belum efektif untuk menjadikan pelajar mampu mendengar, berbicara, menulis, membaca, dan memahami bahasa Arab dengan baik, bahkan belum mampu menginternasionalkan bahasa Arab sebagai media komunikasi dunia, komunikasi bisnis, dan perdagangan tanpa memandang asal dan agama manapun (R, 2006, p. 50). Padahal menurut Dirjen Pembinaan Penempatan Tenaga Kerja (Binapenta) Kemnakertrans Reyna Usman di Jakarta bahwa peluang kerja sebagai TKI formal di Arab 
Suadi sangat besar. Peluang ini harus segera dimanfaatkan oleh para TKI yang hendak bekerja di Arab Saudi dengan mempersiapkan keterampilan bahasa bahasa Arab sebagai salah satu syarat utama menjadi TKI Formal. Selain itu, puncak di mana pemerintah Indonesia merasa bahwa bahasa Arab untuk pemandu wisata adalah pada jelang kunjungan Raja Arab Saudi Salman bin Abdul Aziz Al-Saud ke Bali. Pengusaha pariwisata Bali mengaku kekurangan guide atau pemandu wisata yang bisa berbahasa Arab (Kertasari, 2017).

Meski demikian, mengacu pada kategori LSP-ESP yang telah disebutkan di atas, pada dasarnya di Indonesia sudah banyak lembaga dan instansi yang menyelenggarakan pembelajaran bahasa Arab untuk tujuan khusus, di antaranya pembelajaran bahasa Arab untuk para CTKI (Calon Tenaga Kerja Indonesia) ke Timur Tengah di PT. Mutiara Alamria Jatirangon Jatisampurna Bekasi Jawa Barat (Nasir, 2014). Pembelajaran bahasa Arab untuk mahasiswa jurusan Hubungan Internasional di Pusat Bahasa Universitas Yogyakarta (Wati, 2012). Pembelajaran bahasa Arab bagi calon TKI Arab Saudi di PT. Muhasatama Perdana Bekasi (Hamdani, 2010). Bahkan sebenarnya, pemerintah melalui Kementrian Pariwisata telah mengadakan Workshop Pemandu Wisata Budaya dan Bahasa Arab pada tanggal 13-18 Mei 2016 di Lombok. Hal ini menjadi salah satu bentuk keseriusan pemerintah pusat dalam meningkatkan kualitas SDM di sertor Pariwista.

Bahasa Arab untuk tujuan khusus meski menjadi sorotan dan mendapatkan respon yang positif baik dari kalangan akademisi, praktisi, maupun profesional, akan tetapi dalam segi pelaksanaanya butuh kajian yang mendalam secara teoretis. Sebagaimana dikatakan bahwa konsep bahasa Arab untuk tujuan khusus dalam artikel ini diadaptasi dari konsep ESP. Kini, ESP dianggap sama dengan ELT (English Learning and Teaching) secara umum. Kontroversi ini muncul melalu pertanyaan apakah ESP lebih sukses dan efektif dari pada EGP (English for General Purposes) jika situasi kemampuan siswa berada pada level menengah dan pembelajarannya dilakukan secara komunikatif? Pada saat itu muncul beberapa artikel seperti karya Higgins (1966), Allen dan Widdowson (1974) yang memberikan argumen bahwa ESP mampu meningkatkan perubahan besar terhadap pembelajaran bahasa Inggris. Saat itu juga pada tahun 1960-1970 an, aktivitas ESP memberikan banyak inspirasi terhadap bidang ilmu linguistik terapan seperti Barber, Lakstrom dan Selinker, Trimble. Materi dan produk yang dihasil oleh praktisi ESP seperti Herbert, Swales, Bates dan Dudley-Evans nampaknya lebih dari sekedar teori linguistik terapan (Johns \& Dudley-Evans, 1991, p. 303). Artinya, bahasa Arab untuk tujuan khusus juga dianggap mampu meningkatkan pemahaman bahasa Arab sesuai dengan kebutuhan Link dan Match.

Meski banyak yang membuktikan bahwa ESP layak digunakan oleh semua instruktur dalam pembelajaran bahasa Inggris, akan tetapi masih sedikit sekali penelitian empiris yang menguji efektifitas program ESP (Johns \& Dudley-Evans, 1991, p. 304). Penelitian Awatif Awatif Mohamed Diab membuktikan bahwa LSP-ESP-ASP (PBTK) di Amerika efektif jika dibandingkan dengan pendidikan bahasa Arab untuk tujuan umum. Hasil temuannya, ada lima kebutuhan khusus pembelajaran bahasa Arab di Amerika dengan kategori bahasa Arab untuk tujuan diplomat, bisnis, agama, pekerjaan, dan budaya (Diab, 1997).

Bahasa Arab untuk tujuan khusus di Indonesia dan Malaysia diselenggarakan oleh beberapa lembaga pendidikan, baik lembaga formal maupun non-formal. Yang menarik ditemukan bahwa pembelajaran bahasa Arab untuk tujuan khusus di lembaga formal mayoritas diselenggarakan oleh lembaga pendidikan level perguruan tinggi. Artinya pembelajaran bahasa Arab untuk tujuan khusus lebih praktis bagi siswa tingkat tinggi, 
termasuk mahasiswa yang ada di perguruan tinggi. Hal ini sesuai dengan pendapat Robinson's bahwa LSP-ESP diajarkan untuk pemelajar dewasa di kelas homogen pada masa kerja atau studi khusus yang mereka tekuni (Robinson, 1991, p. 5). Dudley-Evans and St. John dan didukung oleh Rushdi Ahmad Tu'aimah juga berpendapat bahwa LSP (Language for Specific Purposes) didesain untuk pemelajar dewasa baik pada level mahir atau pada situasi kerja (Johns \& Dudley-Evans, 1991; Tu'aimah, 1989). Dari sana, jelas bahwa bahasa Arab untuk tujuan khusus mayoritas diaplikasikan pada pemelajar dewasa atau di tingkat perguruan tinggi. Berikut temuan praktik pembelajaran bahasa Arab di Indonesia dan Malaysia.

\section{Bahasa Arab untuk Tujuan Khusus di Indonesia}

Sebagaimana yang telah disebutkan pada metodologi penelitian, bahasa Arab untuk tujuan khusus dipetakan pada 3 bagian besar, yaitu bahasa Arab untuk tujuan akademik, agama, dan pekerjaan. Di Indonesia di temukan praktik pembelajaran bahasa Arab untuk tujuan akademik yang ada di Sekolah Tinggi Filsafat Islam (STFI) Sadra Jakarta, sedangkan untuk tujuan agama ada di LBIQ-Jakarta, dan untuk tujuan pekerjaan ada di PT. Mutiara Alamria-Bekasi, sebagaimana temuan-temuan secara detail pada gambar 1 sebagai berikut:

Gambar 1. Bahasa Arab untuk Tujuan Khusus di Indonesia

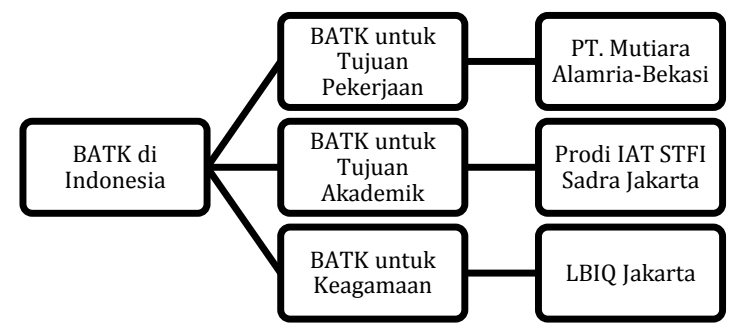

\section{Bahasa Arab Untuk Tujuan Akademik di STFI Sadra Jakarta}

Pembelajaran bahasa Arab untuk tujuan akademik telah dilakukan oleh STFI Sadra. STFI Sadra memiliki dua Prodi untuk Strata 1 yaitu Prodi Al-Quran dan Tafsir (IAT) dan Prodi Filsafat Islam. Sedang untuk jenjang Strata 2 ada satu Prodi yaitu Filsafat dengan berbagai macam konsentrasi, mulai konsentrasi Filsafat Agama, Filsafat Jiwa, Filsafat Pendidikan, dan lain sebagainya.

Setelah dilakukan penelitian, bahasa Arab untuk tujuan khusus telah dilakukan oleh Prodi IAT dan Filsafat Islam jenjang S1. Yang menarik di sini, mahasiswa Prodi IAT dan Filsafat Islam wajib mengikuti matrikulasi bahasa Arab yang diselenggarakan oleh STFI Sadra Jakarta selama 1 tahun secara intensif dengan Program Tarbiyatul Muhaqqiqin (TM). TM merupakan program unggulan STFI Sadra yang menyelenggarakan pembelajaran bahasa Arab secara intensif dalam rangka menyiapkan dan menyetarakan kemampuan bahasa Arab mahasiswa sehingga mereka mampu mengkaji bidang konsentrasinya dengan baik dan maksimal. Sebab Prodi IAT dan Filsafat Islam perlu ditunjang kemampuan bahasa Arab yang memadai untuk mengkaji literatur-literatur induknya yang mayoritas berbahasa Arab. Artinya, STFI Sadra sangat menyadari pentingnya praktik pembelajaran bahasa Arab. Setelah mahasiswa dinyatakan lulus program TM Bahasa Arab, pada tahun kedua mahasiswa masih tetap diberikan mata kuliah khusus bahasa Arab yang lebih khusus diarahkan kepada bagaimana memahami teks bahasa Arab dengan cepat dan baik sesuai bidangnya. Oleh karena itu, penelitian ini 
difokuskan pada praktik pembelajaran bahasa Arab untuk tujuan akademik mahasiswa Prodi IAT. Artinya, teks yang difokuskan dalam pembelajarannya adalah teks-teks Alquran dan karya-karya Tafsir serta literatur dan jurnal lain berbahasa Arab yang otoritatif.

Untuk melihat praktik pembelajaran bahasa Arab untuk tujuan akademik mahasiswa IAT STFI Sadra Jakarta, penting dilihat kurikulum dan silabus yang digunakan. Tujuan pembelajaran bahasa Arab di IAT untuk mahasiswa semester 3 ke atas agar mahasiswa mampu memahami teks dan literatur Alquran dan tafsir dengan baik sesuai dengan bidang kajian mereka. Menurut hasil wawancara dengan dosen yang ada, silabus yang digunakan adalah silabus berbasis teks tafsir. Setiap pertemuan mahasiswa mengakaji karya-karya tafsir seperti, tafsir Al-Amthal karya Makarim Syirazi, Tafsir al-Mizan karya Taba'tabai, Tafsir Al-Quran al-'Azim karya Ibnu Kathir, dan lain sebagainya. Secara kasat mata, silabus yang ada sama sekali tidak menampakkan pembelajaran bahasa Arab, yang terlihat hanya pembelajaran tafsir. Padahal dalam praktiknya, mahasiswa mempelajari bahasa Arab yang mengacu pada teks tafsir.

Dari silabus yang ada, metode dan pendekatan yang digunakan di kelas adalah integrasi dua pendekatan mutakhir dalam pembelajaran bahasa asing, CLIL (Content and Language Integrated Learning) dan LSP (Language for Specific Purposes). Kedua strategi ini sama-sama mencoba mengarahkan pembelajaran bahasa dalam konteks dan realitas empiris. Meski demikian, CLIL dan LSP memiliki perbedaan yang mendasar dalam operasionalnya. CLIL lebih mengarah pada sistem pembelajaran dual-focus yang tidak hanya berorientasi kepada pemahaman konten namun juga bahasa secara bersamaan. Artinya, selain memahami teks-teks kajian ilmu tertentu yang berbahasa Arab, mahasiswa juga harus memahami bahasa Arab yang menjadi bahasa yang digunakan konten tersebut. Berbeda dengan CLIL, LSP merupakan konsep pembelajaran bahasa yang mengacu pada tujuan dan kebutuhan mahasiswa yang diawali dengan analisis kebutuhan (need analysis) (Mahmud, 1983, p. 115). Konsep LSP merupakan kebalikan dari konsep CLIL dalam operasionalnya. Jika CLIL fokus kajianya ada pada konten baru kemudian bahasa, LSP fokus kajiannya justru ada pada bahasa itu sendiri baru kemudian mengkaji konten.

Evaluasi yang digunakan dalam pembelajaran bahasa Arab adalah dengan menggunakan tes dan non tes. Untuk tes, tujuan yang difokuskan adalah pemahaman mahasiswa terkait kajian tafsir melalui keterampilannya memahami teks-teks Arab yang digunakannya. Dosen memberikan tes non tulis (shafawi) kepada mahasiswa secara spontan. Tolok ukur keberhasilannya dilihat dari penjelasan dan pemahaman siswa dalam menyampaikan isi dan makna teks.

\section{Bahasa Arab untuk Tujuan Pekerjaan di PT. Mutiara Bahari Alamria Bekasi}

Praktik pembelajaran bahasa Arab untuk tujuan khusus, dalam hal ini untuk tujuan pekerjaan telah dilakukan oleh PT. Mutiara Bahari Alamria Jatirangon Jatisampurna, Bekasi. PT tersebut merupakan perusahaan yang menyelenggarakan pembelajaran bahasa Arab untuk CTKI ke Timur Tengah dengan mengacu pada Undang-Undang No. 39 Tahun 2004 tentang Penempatan dan Perlindungan Tenaga Kerja Indonesia di Luar Negeri pasal 42. Di samping itu. Praktik pembelajaran bahasa Arab di sana juga merupakan upaya menyiapkan para CTKI untuk menghadapi ujian kompetensi sertifikasi profesi bagai CTKI, termasuk kompetensi bahasa Arab. Dengan mengikuti ujian tersebut, mereka akan mendapatkan sertifikat dari BNSP sebagai salah satu syarat legal bekerja sebagai TKI di Timur Tengah. 
Dari hasil penelitian lapangan yang telah dilakukan oleh Abu Nasir pada tahun 2014 (Nasir, 2014) ditemukan bahwa tujuan pembelajaran BA di PT MBA adalah agar CTKI mampu berkomunikasi secara lisan bahasa Arab yang sesuai kebutuhan CTKI yaitu bahasa Arab untuk konteks asisten rumah tangga. Mengingat kemahiran bahasa yang diutamakan adalah kemahiran berbicara bahasa Arab, maka pendekatan yang digunakan adalah pendekatan CBLT (Pembelajaran Berbasis Kompetensi) yang praktis sama seperti pendekatan komunikatif. Selain itu, strategi pembelajaran yang digunakan hanya berfokus pada pembelajaran kosakata (mufradat), keterampilan berbicara, dan sedikit keterampilan mendengar. Kurikulum dan silabus yang ada masih sangat sederhana, belum ada rincian pelaksanaan pembelajarannya ketika di kelas. Meski demikian, topik dan materi yang diajarkan secara umum sudah sesuai dengan kebutuhan mereka terkait dalam konteks penata laksana rumah tangga.

Yang menarik ditemukan bahwa instruktur yang ada merupakan ahli di bidang kerja tatalaksana rumah tangga, yang dua duanya lulusan akademi pariwisata, namun kurang ahli di bidang pengajaran. Di tambah lagi dengan penguasaan bahasa Arab mereka yang diperoleh secara otodidak dan dari hasil intensif berkomunikasi dengan TKI yang ada di Timur Tengah. Sedangkan, latar belakang CTKI yang ada berasal dari beragam bahasa, budaya, dan tingkat pendidikan. Mayoritas mereka merupakan orang dewas, sudah menikah, dan berkeluarga. Rata-rata mereka lulusan SD dan SMP dan sedikit yang berpendidikan SMA. Secara umum, motivasi mereka menjadi CTKI adalah untuk membantu ekonomi keluarga.

Salah satu hal menarik lagi yang ditemukan dalam pembelajaran, media yang digunakan sangat kontekstual dan konkret, karena selain media yang sudah baku seperti proyektor, LCD, dan CD interaktif, instruktur menggunakan media konkret seperti vacuum cleaner, karpet, baju-baju budaya Arab dalam mengajarkan kosakata sehingga mudah dimengerti dan mempermudah CTKI dalam memahami kosakata tersebut. Selain media konkret, media yang digunakan dalam pembelajaran adalah gambar dan video, animasi, dan lain sebagainya. Sebagaimana disebutkan di atas bahwa materi yang ada dalam silabus cukup sesuai dengan konteks asisten rumah tangga, seperti kosakata tentang bidang kerja PLRT, ungkapan-ungkapan komunikasi yang sering digunakan. Yang menarik juga ditemukan bahwa aksara yang digunakan adalaj aksara Latin, bukan aksara Arab dengan menggunakan ragam bahasa Arab Ammiyyah yang komunikatif dalam konteks PLRT.

Evaluasi pembelajaran bahasa Arab dilakukan oleh BLKLN MBA pada setiap pembelajarannya. Setiap pertemuan, instruktur melakukan evaluasi lisan dan tulisan tentang kosakata yang telah diajarkan. Evaluasi pembelajaran dilakukan secara internal dan ekternal. Untuk internal dilakukan oleh BLKLN dan ekternal oleh LSP (Lembaga Sertifikasi Profesi) secara independen yang secara langsung ditunjuk oleh BNSP (Badan Nasional Sertifikas Profesi).

Yang menarik juga ditemukan dari hasil obeservasi lapangan secara langsung, PT. Mutiara Bahari Alamria Jatirangon Jatisampurna, Bekasi kini sudah tidak beroperasi lagi. Itu artinya, pembelajaran bahasa Arab untuk tujuan khusus yang ada di sana sudah tidak dipraktikkan lagi. Meski demikian, menjadi sebuah temuan bahwa pembelajaran bahasa Arab untuk tujuan pekerjaan telah ada di Indonesia.

\section{Bahasa Arab untuk Tujuan Agama dan Alquran di LBIQ DKI Jakarta}

LBIQ (Lembaga Bahasa dan Ilmu Al-Qur'an) merupakan salah satu lembaga yang menyelenggarakan pembelajaran bahasa Arab untuk tujuan khusus. Sebab LBIQ 
memiliki program kurus bahasa Arab untuk tujuan memahami Alquran. Oleh karena itu, LBIQ merupakan lembaga yang menyelenggarakan praktik pembelajaran bahasa Arab untuk tujuan Agama dan Alquran. Mengacu pada pemetaan Dudley Evan, maka kategori ini tidak ada dalam kategorisasi yang telah ada yaitu untuk tujuan akademik dan pekerjaan. Meski kategori ini terkesan memiliki kekhususan yang berbeda, namun jika diteliti kembali, LBIQ merupakan lembaga yang menyelenggarakan pembelajaran bahasa Arab untuk tujuan akademik.

Perlu diketahui bahwa (LBIQ) Provinsi DKI Jakarta dibentuk melalui Surat Keputusan Gubernur Kepala Daerah Provinsi DKI Jakarta Nomor 2745 tahun 1984 yang disempurnakan dengan Keputusan Gubernur DKI Jakarta Nomor 83 tahun 1986 dan terakhir disempurnakan lagi dengan Peraturan Gubernur Provinsi Daerah Khusus Ibukota Jakarta Nomor 42 tahun 2014 tentang Pembentukan Organisasi dan Tata Kerja Lembaga Bahasa dan Ilmu Al-Qur'an Provinsi Daerah Khusus Ibukota Jakarta. LBIQ adalah lembaga non perangkat daerah di bidang keagamaan yang menyelenggarakan pendidikan dan pengajaran bahasa dan Ilmu Alquran di Provinsi Daerah Khusus Ibukota Jakarta yang dipimpin oleh seorang Kepala Lembaga yang berada di bawah dan bertanggung jawab langsung kepada Gubernur melalui Dewan Pembina. Dalam melaksanakan tugasnya LBIQ di bawah koordinasi Biro Pendidikan dan Mental Spiritual Setda Provinsi DKI Jakarta pada Sekretaris Daerah.

LBIQ mempunyai tugas pokok menyelenggarakan Pendidikan dan Pengajaran Bahasa dan Ilmu Alquran serta penelitian dan pengembangan materi dan metodenya. Fungsi LBIQ adalah menyusun rencana dan program LBIQ; menyelenggarakan pendidikan dan pengajaran bahasa, membaca dan memahami isi dan makna Alquran; menyelenggarakan penelitian dan pengembangan materi dan metode pendidikan dan latihan tenaga pengajar, pengajaran bahasa, membaca dan memahami isi dan makna Alquran; menyelenggarakan pendidikan dan latihan tenaga pengajar (instruktur) untuk pengajaran bahasa, membaca dan memahami isi dan makna Alquran; menyelenggarakan kegiatan perpustakaan, dokumentasi dan publikasi; menyelenggarakan hubungan kerja sama dengan instansi/lembaga lain di bidang Bahasa dan llmu Alquran; dan melaksanakan ketatausahaan yang meliputi surat menyurat kepegawaian, keuangan dan kerumahtanggaan.

Salah satu program unggulan LBIQ adalah program pembelajaran bahasa Arab Qurani. Bahasa Arab yang diajarkan diarahkan pada kepentingan memahami Alquran dan agama Islam. Oleh karena itu materi yang dikaji adalah materi-materi kegamaan dan ibadah yang sangat dibutuhkan oleh umat Muslim awam di DKI Jakarta. Salah satu buku yang digunakan adalah Bahasa Arab Qurani karya Prof. Dr. HD. Hidayat, MA. Bahasa Arab Quran menggunakan teks ayat-ayat Alquran. Program pembelajaran bahasa Arab untuk tujuan memahami Alquran bertujuan untuk membimbing peserta didik agar dapat menguasai kosakata Arab yang mengacu pada teks Alquran sebagai modal memahami Alquran, Hadis, dan kitab-kitab agama Islam yang berbahasa Arab, serta menumbuhkan sikap dan mental positif terhadap bahasa Arab dalam rangka meningkatkan kualitas ibadah dalam rangka meningkatkan keimanan dan ketaqwaan kepada Allah SWT.

Materi bahasa Arab diajarkan secara bertahap sesuai dengan kemampuan peserta didik. Materi diambil dari teks-teks Alquran, Hadis, dan teks-teks yang sering digunakan untuk beribadah sehari-hari terutama dalam sholat. Materi yang diajarkan sebagai berikut.

1. Unsur-unsur bahasa Arab, seperti kata melalui pelajaran Shorof, kalimat yang diajarkan melalui ilmu Nahwu, dan kosakata (mufradat), dan bahan bacaan dari teks Alquran; 
2. Kegiatan berbahasa yang difokuskan pada kegiatan membaca untuk melatih keterampilan membaca (maharah al-Qira'ah) mereka sehingga mereka terampil dengan baik dan benar membaca teks Arab Alquran serta memahaminya;

Sebagaimana dijelaskan di atas bahwa pembelajaran bahasa Arab di LBIQ disesuaikan dengan tingkat kemampuan peserta didik. Ada 6 tingkat yang tersedia dalam program ini yaitu Tingkat Dasar I, II, dan III; Tingkat Menengah I, II, III. Dari sana terlihat jelas bahwa mayoritas peserta yang ikut kursus hanya memiliki kemampuan di tingkat dasar dan menengah, tidak ada yang ada pada tingkat tinggi (advanced). Pada kasus seperti ini, program bahasa Arab untuk tujuan khusus yang dipraktikkan oleh LBIQ DKI Jakarta selaras dengan pendapat Dudley-Evans and St. John yang mengatakan bahwa kursus LSP bisa digunakan untuk pemula (Johns \& Dudley-Evans, 1991, 302). Bahkan juga sependapat dengan Anthony yang mengatakan bahwa LSP bisa dipelajari bagi para pemula setelah mereka memeroleh dasar-dasar bahasa. Perlu diketahui bahwa dalam 1 tingkatan atau level, proses pembelajarannya membutuhkan waktu 72 jam, dengam rincian 45 menit/jam, itu berarti ada 36 kali pertemuan untuk menuntaskan setiap level.

Secara umum, program ini telah berhasil meningkatkan kesadaran bagi umat Islam akan pentingnya bahasa Arab dan mampu memacu umat Islam khusus Muslim di DKI Jakarta untuk mengkaji ajaran agama Islam langsung dari sumber aslinya, Alquran, Hadis, dan Kita-kitab keagamaan yang otoritatif lainnya, bukan dari karya terjemahan.

\section{Bahasa Arab untuk Tujuan Khusus di Malaysia}

Pembelajaran bahasa Arab untuk tujuan khusus di Malaysia belum terungkap secara detail. Meski demikian, pekembangannya dapat terlihat melalui kajian-kajian dan penelitian terkait pembelajaran bahasa Arab untuk tujuan khusus, bahkan sudah sampai pada tataran merancang dan mendesain kurikulumnya mulai tahun 1988-2009. Abdul Rahman menyatakan bahwa pembelajaran bahasa Arab untuk tujuan khusus di Malaysia telah lama digagas, seperti bahasa Arab untuk mahasiswa fakultas hukum dan ekonomi di Universitas Islam Malaysia (A. R. Chik, personal communication, July 3, 2018). Berikut klasifikasi bahasa Arab untuk tujuan khusus di Malaysia yang dipetakan pada gambar 2.

Gambar 2. Bahasa Arab untuk Tujuan Khusus di Malaysia

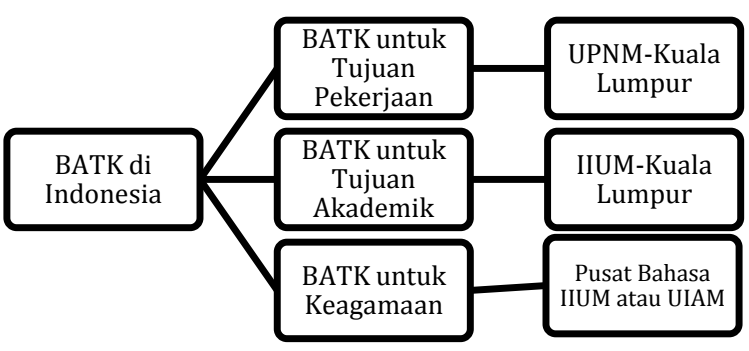

\section{Bahasa Arab untuk Tujuan Akademik di IIUM-Kuala Lumpur}

Salah satu lembaga yang menyelenggarakan pembelajaran bahasa Arab untuk tujuan khusus adalah IIUM (International Islamic University Malaysia) yang populer dengan Universitas Islam Antarabangsa Malaysia. IIUM adalah universitas yang unik baik di Malaysia maupun di dunia yang disponsori oleh 8 pemerintahan yang berbeda dari Organisasi Konferensi Islam (OIC). Bahkan salah satu fakultasnya secara eksplisit menyelenggarakan program Master of Arts Teaching Arabic for Specific Purposes di Kulliyyah of Languages and Management. KLM merupakan fakultas yang ada di IIUM 
yang didirikan pada tahun 1991 oleh Komite Perencanaan Pendidikan (Jawatan kuasa Perancang Pendidikan) dari Departemen Pendidikan yang berfokus pada kajian bahasa. Fakultas ini bermula terdiri dari 4 Prodi, Prodi Bahasa Inggris, Arab, Melayu dan Manajemen Pariwisata \& Perhotelan. Perkuliah dimulai dengan program Bahasa Arab dan Bahasa Inggris untuk Komunikasi Internasional. Fakultas ini juga menyelenggarakan program sarjana dan pascasarjana Bahasa Inggris dan Bahasa Arab dan Studi Sastra. Selain itu juga menawarkan kursus kemahiran bahasa Arab Modern, Inggris, Melayu, Jepang, Perancis dan Mandarin.

Program Magister Arabic for Specific Purposes (MA-ASP) didirikan sebagai respon dari sering gagalnya bahasa Arab untuk tujuan umum memenuhi kebutuhan peserta didik dengan tujuan atau minat tertentu. Oleh karena itu, program ini dirancang untuk memenuhi kebutuhan-kebutuhan yang berfokus pada bidang khusus seperti Bisnis, Pariwisata, Medis, haji dan umrah dan lain-lain. Jadi, mahasiswa mampu mendapatkan pembelajaran tentang budaya kerja dan akademik. Hal ini membuktikan bahwa pembelajaran bahasa Arab untuk tujuan di Malaysia sangat maju.

Pembelajaran bahasa Arab untuk tujuan khusus akademik di Malaysia juga dipraktikkan oleh Akademi Pengajian Islam, Universiti Malaya (APIUM) yang ada di kampus cawangan APIUM di Nilam Puri, Kelantan (Dahan \& Zailaini, 2005). APIUM menyelenggarakan pembelajaran bahasa Arab untuk tujuan khusus pada program pra Universitas. Pada program tersebut, bahasa Arab digunakan sebagai bahasa pengajaran pada sebagian besar mata kuliah. Meski terdapat perkuliahan yang menggunakan bahasa Melayu, akan tetapi sebagaian besar mahasiswa APIUM menggunakan literatur dan rujukan berbahasa Arab. Fakta ini meniscayakan mahasiswa untuk menguasai bahasa Arab dengan baik. Bahkan menurut hasil penelitian Isahak Haron pada tahun 2000 menunjukkan $45 \%$ bahan rujukan mahasiswa APIUM adalah literatur-literatur dalam Bahasa Arab, sementara penggunaan referensi dalam Bahasa Inggris tidak lebih dari 2.6 $\%$, dan 52.6\% menggunakan referensi berbahasa Melayu (Haron, 2000). Hasil tersebut meniscayakan para dosen untuk melatih kemahairan membaca dan menulis teks Arab di kalangan mahasiswa APIUM tanpa mengabaikan dua kemahiran mendengar dan berbicara justru sebenarnya merupakan kemahiran pertama yang harus dikuasai dalam berbahasa.

Bahkan dosen bahasa Arab untuk kajian Syariah dan Ushuluddin di APIUM justru tidak ingin mahasiswa menganggapnya sebagai seorang ahli Fiqih atau Mufassir, akan tetapi ia ingin para mahasiswa menganggapnya sebagai seorang dosen yang mampu membantu mereka menjelaskan dalam bahasa Arab tentang Fiqih dan Ilmu Alquran. Hal ini menjadi sebuah tantangan bagi dosen bahasa Arab untuk menguasai bidang pengkhususan di APIUM. Oleh karena itu, kebanyakan dosen bahasa Arab yang mengajar di APIUM mengambil pengkhususan minor dalam bidang Syariah atau Usuluddin. Bahkan sebagian dari mereka mempunyai latarbelakang bidang yang sama dengan bidang mahasiswa APIUM. Hal ini sangat mendukung praktik pembelajaran bahasa Arab untuk tujuan khusus di APIUM.

Bahan ajar yang digunakan dalam pembelajaran bahasa Arab untuk tujuan kusus harus tetap bertujuan untuk penguasaan bahasa Arab, bukan penguasaan bidang yang dikaji oleh mahasiswa seperti Syariah, Fiqih, atau bidang lainnya. Oleh karena itu, pembelajaran bahasa Arab tidak harus diajarkan secara mandalam, hanya materi yang relevan saja yang diajarkan sehingga tujuan pembelajaran bahasa Arab tercapai dengan baik. Di APIUM misalkan dosen menggunakan artikel tentang Syariah dan Fiqih dalam bahasa Arab. Artikel tersebut hanya digunakan sebagai alat mempelajari bahasa Arab 
untuk tujuan khusus, bukan untuk mempelajari bidang Syariah dan Fiqih. Waktu yang sangat menentukan keberhasilan menguasai kemahiran membaca dengan baik (Krashen, 2004). Hal ini sama persis dengan kasus yang ada di APIUM terkait pembelajaran bahasa Arab.

Mengacu pada fakta pembelajaran bahasa Aran di APIUM dan analisis kebutuhan mahasiswa, dosen APIUM menyiapkan pembelajaran bahasa Arab yang sesuai dengan kebutuhan mahasiswa. Mengacu pada materi pembelajaran bahasa Arab di APIUM, tujuan akhir mahasiswa Syariah dan Usuluddin adalah untuk menjadi ahli Fiqih, Mufassir, dan ahli pendidikan Islam. Hal ini mengingat bahwa masa studi Sarjana Muda di APIUM adalah empat tahun. Hal ini sangat tidak memungkinkan mahasiwa mampu menguasai kajian bahasa Arab secara mendalam seperti Nahwu (Sintaksis Arab), Shorof (Morfologi Arab), Balaghah (Stilistika Arab), Dilalah (Semantik Arab), 'Ilmu Aswat (Fonetik dan Fonologi Arab), dan lain sebagainya. Dosen APIUM menentukan topik yang sesuai dengan level mahasiswa. Untuk pra universitas, topik yang dipilih cenderung mudah dan tidak akan diulang lagi topik yang sama pada level lanjutan sehingga silabus dapat disusun dengan mudah khususnya dalam penentuan topik untuk bahan pembelajaran bahasa Arab.

Sebagaimana tujuan APIUM yang mencanangkan agar mahasiswa lulusan APIUM menjadi ahli Fiqih, ahli Tafsir, dan ahli dalam bidang pendidikan Islam. Seperti mahasiswa Sarjana Muda Pendidikan Islam yang menggunakan buku diktat bahasa Arab, Nahwu Wajiz (junctional grammar) yang topik-topik kajiannya merujuk pada Alquran dan Hadis yang menjadi sumber utama kajian Syariah dan Usuluddin. Bukan hanya itu, seperti kajian ilmu Balaghah ilmu Ma'ani dan ilmu Bayan dipraktikkan akan tetapi ilmu Badi' tidak, sebab secara praktis ilmu Badi' tidak dibutuh secara eksplisit dalam kajian Syariah dan Hukum. Selain mempelajari ilmu-ilmu Bahasa Arab, mahasiswa Syariah dan Usuluddin juga dilatih kemahiran berbicara dan menulis dalam Bahasa Arab. Oleh karena itu, mereka juga diberikan materi yang fokus melatih kemahiran membaca dan menulis. Mata kuliah analisis wacana dan teks dalam Pendidikan Bahasa Arab juga diajarkan agar mereka mampu menguasai gaya Bahasa Arab dalam rangka meningkatkan kualitas tulisan mereka.

\section{Bahasa Arab untuk Tujuan Pekerjaan di UPNM-Kuala Lumpur}

Salah satu lembaga yang menjadi objek penelitian di Malaysia adalah UPNM (Universiti Pertahanan Nasional Malaysia). UPNM merupakan perguruan tinggi khusus mendidik calon tentara dan militer Malaysia. Pada tahun 2010, Pusat Pengurusan Pengajian Eksekutif (PPPE) telah mendirikan organisasi yang menyelenggarakan pendidikan dan kursus dalam upaya mendidik Angkatan Tentera Malaysia (ATM), Perbadanan Hal Ehwal Bekas Angkatan Tentera (PERHEBAT), dan lembaga pertahanan negera baik negeri maupun Swasta. Uniknya UPNM juga memiliki Pusat Bahasa (LC). LC UPNM merupakan adalah pusat akademik termuda di Universitas Pertahanan Nasional Malaysia. Sebelumnya dikenal sebagai Centre for Liberal and Language Studies (CLLS), yang mengakomodir kebutuhan baru di UPNM.

Pusat Bahasa ini didirikan untuk mempromosikan pengetahuan dan keterampilan global yang dibutuhkan oleh pejabat militer dan sipil Malaysia. Kursus yang ditawarkan oleh pusat bahasa adalah kursus yang bersifat wajib. Di sntsrs kursus yang diselenggarakan adalah kursus bahasa Inggris dan kursus bahasa asing termasuk Arab, Spanyol, Perancis, Mandarin, Jepang dan Rusia yang diarakan pada wacana dan pemikiran kritis, keterampilan membaca dan belajar serta sastra. 
Pembelajaran bahasa Arab di UPNM diarahkan pada semangat mempelajari budaya global Arab. Artinya, pembelajaran bahasa Arab di UPNM tidak begitu ditekankan mengingat minat dan motivasi mahasiswa yang kurang terhadap bahasa Arab. Oleh karena itu, pembelajarannya lebih diarahkan pada bagaimana memotivasi mahasiswa melalui kegiatan pembelajaran yang menyenangkan dan percakapan yang komunikatif. Mahasiswa diikutkan dalam kegiatan kompetisi bahasa Arab seperti debat bahasa Arab, pidato bahasa Arab, dan lain sebagainya. Mahasiswa yang berprestasi mendapatkan apresiasi dan reward yang tinggi dari universitas. Bahkan, meski yakin akan kalah dalam perlombaan, mahasiswa diikutkan kompetisi antar universitas (N. S. Abd. Razak, personal communication, July 3, 2018). Hal ini untuk memotivasi dan meningkatkan minat mahasiswa dalam bahasa Arab. Meski demikian, keterampilan yang difokuskan untuk mahasiswa adalah keterampilan berbicara dan berkomunikasi bahasa Arab dalam rangka menyiapkan karir mereka nanti sebagai milter Malaysia, di mana nantinya mereka akan berkomunikasi antar budaya lain termasuk Arab.

Ada yang menarik di sini, salah satu evaluasi yang dilakukan oleh pusat bahasa dalam mengukur kemampuan komunikasi mahasiswa dengan magang di keluarga penutur asli bahasa Arab atau keluarga yang berwarganegera Arab dan Timteng, dengan komposisi 6 orang dalam 1 keluarga. Mahasiswa ditugaskan magang kurang lebih dua hari dan dituntut secara aktif berkomunikasi dengan anggota keluaga dengan menggunakan bahasa Arab. Penilaian kompetensi keterampilan berbicara bahasa Arab mahasiswa dilakukan oleh orang Arab langsung. Metode evaluasi seperti ini menurut wakil ketua Pusat Bahasa UPNM cukup efektif dalam memotivasi mahasiswa mencintai bahasa Arab dan mendapatkan pemerolehan bahasa Arab langsung dari penutur aslinya (Faisal, personal communication, July 3, 2018).

Dari data tersebut dapat disimpulkan bahwa pembelajaran bahasa Arab di UPNM bisa dibilang merupakan bahasa Arab untuk pekerjaan dan karirnya. Sebab, salah satu posisi yang memungkinkan dijabat oleh mereka adalah sebagai petugas haji yang nantinya akan mengamankan jamaah haji Malaysia, yang popular dengan Angkatan Tentera Malaysia (ATM) khususnya Kor Agama Angkatan Tentera (KAGAT). Para KAGAT nantinya bertugas di Arab Saudi yang meniscayakan mereka memiliki kompetensi bahasa Arab.

\section{Bahasa Arab untuk Tujuan Ibadah di Pusat Bahasa IIUM}

Muhammad Sabri Sahrir dkk juga telah mengungkap model pembelajaran bahasa Arab untuk tujuan khusus di Malaysia yang khusus untuk tujuan ibadah bagi masyarakat awam (Sahrir et al., 2013). Hal ini mengacu pada sebuah fakta bahwa bahasa Arab merupakan bahasa yang digunakan dalam ritual ibadah agama Islam, seperti sholat dan haji. Fakta ini meniscayakan umat Islam untuk mempelajari bahasa Arab secara baik dan serius. Bahkan hasi sebuah penelitian mengenai kecenderungan orang awam Hal ini mengacu pada sebuah analisis kebutuhan yang dilakukan pada masyarakat muslim awam melalui facebook. Hasil analisis tersebut menunjukkan bahwa masyarakat awam membutuhkan bahasa Arab untuk memahami bacaan-bacaan dalam ibadah seperti sholat dan haji.

Tuntutan untuk mempelajari bahasa Arab tidak hanya bertumpu kepada golongan tertentu yang menjurus kepada tujuan akademik, malah ia turut menjadi satu keperluan bagi masyarakat awam yang beragama Islam. Bagi peringkat tinggi pula, banyak institusi pengajian tinggi awam menawarkan program pengajian bahasa Arab seperti di Universiti 
Malaya (UM), Universiti Islam Antarabangsa Malaysia (UIAM), Universiti Kebangsaan Malaysia (UKM).

Pusat bahasa IIUM menyelenggaran pembelajaran bahasa Arab untuk tujuan keagamaan untuk memahami Alquran dan ibadah untuk orang awam. Uniknya, pembelajaran bahasa Arab di sana sudah mapan dalam hal modul dan buku ajar. Buku ajar dan modul yang didesain mulai dari Nahwu mudah atau pemula dan gramatika bahasa Arab sederhana baru kemudian diarahkan pada penerjemahan Alquran perkata (M. Sabri, personal communication, 3 Juli).

\section{KESIMPULAN}

Dari temuan dan analisis data yang ada, dapat disimpulkan bahwa bahasa Arab untuk tujuan khusus di Indonesia dan Malaysia telah ada di beberapa lembaga pendidikan bahasa Arab baik formal maupun informal. Bahasa Arab untuk tujuan khusus di Indonesia yang dipraktikkan oleh STFI Sadra Jakarta bertujuan agar mahasiswa memahami teks dan literatur Alquran dan tafsir. Selain itu, Praktik pembelajaran bahasa Arab di PT. Mutiara Bahari Alamria Jatirangon Jatisampurna, Bekasi bertujuan agar peserta didik mampu berkomunikasi secara lisan yang sesuai kebutuhan CTKI yaitu bahasa Arab dalam konteks asisten rumah tangga. Praktik pembelajaran bahasa Arab untuk tujuan khusus di LBIQ Jakarta yaitu melalui program pembelajaran bahasa Arab Qurani. Bahasa Arab yang diajarkan diarahkan pada kepentingan memahami Alquran dan agama Islam dengan menggunakan teks ayat-ayat Alquran sebagai bahan ajar.

Bahasa Arab untuk tujuan akademik di IIUM (International Islamic University Malaysia) adalah program Master of Arts (M.A) Teaching Arabic for Specific Purposes di Kulliyyah of Languages and Management yang diselenggarakan untuk memenuhi kebutuhan-kebutuhan yang berfokus pada bidang khusus seperti Bisnis, Pariwisata, Medis, haji dan umrah dan lain-lain. Pembelajaran bahasa Arab untuk tujuan khusus akademik di Malaysia juga dipraktikkan oleh Akademi Pengajian Islam, Universiti Malaya (APIUM) pada program pra Universitas. Bahan ajar yang digunakan artikel tentang Syariah dan Fiqih dalam bahasa Arab. Praktik pembelajaran bahasa Arab untuk tujuan pekerjaan di UPNM-Kuala Lumpur mempraktikkan strategi dalam pembelajarannya dengan kegiatan kompetisi bahasa Arab seperti debat bahasa Arab, pidato bahasa Arab, dan magang di keluarga penutur asli bahasa Arab. Praktik pembelajaran Bahasa Arab untuk tujuan Ibadah di Pusat Bahasa IIUM diselenggarakan untuk memahami Alquran dan ibadah untuk orang awam dengan modul dan buku ajar yang sudah mapan

\section{UCAPAN TERIMA KASIH}

Terima kasih kepada Pusat Penelitian dan Pengabdian (Puslitpen) Lembaga Penelitian dan Pengabdian Masyarakat (LP2M) UIN Syarif Hidayatullah Jakarta yang telah memberikan hibah penelitian kepada penulis pada tahun 2018 sehingga penulis bisa secara langsung melakukan penelitian di Indonesia dan di Malaysia 


\section{REFERENSI}

Abdallah, F. (2006, March 25). The Making of an Arabic Curriculum. ISNA Educational Forum.

Al-Khulli, M. A. (1986). Asalib Tadris al-Lughah al-'Arabiyah. Maktabah Al-Farazdaq.

Amayirah, I. A. (1996). Buhuth fi al-Istishraq wa al-Lughah. Muassasah al-Risalah.

Arsyad, A. (2003). Bahasa Arab dan Metode Pengajarannya. Pustaka Pelajar. Pustaka Pelajar.

Belnap, R. K. (1992). Teaching Arabic as a Foreign Language: Challenges of the Nineties, The Teaching of Arabic as a Foreign Language Issues and Directions, The Teaching of Arabic in the 1990s: Issues and Directions, 1992. Al-Arabiyya Journal of the American Association of Teachers of Arabic.

Chik, A. R. (1988). Teaching Arabic for Specific Purposes (ASP) With Special Reference To Teaching Reading Skills at the International Islamic University [MA. Thesis]. University of Salford.

Dahan, H. B. A. M., \& Zailaini, M. A. (2005). Pengajaran Bahasa Arab untuk Tujuan-khusus: Satu Pandangan Awal [Teaching Arabic Language for special purposes: An early view]. Masalah Pendidikan, 28(01), 233-244.

Diab, A. M. (1997). Teaching Arabic for Specific Purposes in America," Ph.D Thesis, Faculty of the College of Arts and Science, American University, 1997). American University.

Faisal. (2018, July 3). Pembelajaran Bahasa Arab di UPNM [Personal communication].

Hamdani. (2010). Tujuan Metode Pembelajaran Bahasa Arab dan Tingkat Keberhasilannya bagi Calon Tenaga Kerja Indonesia Arab Saudi di PT. Mahasatama Perdana Bekasi. UIN Sunan Kalijaga Yogyakarta.

Haron, I. (2000). Kajian Penggunaan Bahan Rujukan oleh Pelajar UM untuk Quality Assurance Data.

Johns, A. M., \& Dudley-Evans, T. (1991). English for Specific Purposes: International in Scope, Specific in Purpose. TESOL Quarterly, 25(2).

Kertasari, K. (2017, Oktober). Jelang Kunjungan Raja Salman Agen Perjalanan di Bali Kekurangan Pemandu Wisata Fasih Berbahasa Arab. https://daerah.sindonews.com/read/1183345/174/agen-perjalanan-di-bali-kekuranganpemandu-wisata-fasih-berbahasa-arab-1488071719,

Krashen, S. D. (2004). The Powe of Reading: Insights from the Research (2nd ed.). Libraries Unlimited.

Madkur, A. A., \& Huraidi, I. A. (2006). Ta'lim al-Lughah al- 'Arabiyah li Ghair al-Nathiqin Biha al-Nadzariyah wa al-Tathbiq. Dar al-Fikr al-'Arabi.

Mahmud, I. A. (1983a). Ta'lim al-Lughah li Aghradin Muhaddadah. Al-Majallah al- 'Arabiyah Li al-Dirasat al-Lughawiyah. 
Mahmud, I. A. (1983b). Ta'lim al-Lughah li Aghradlin Muhaddadah. Al-Majallah al- 'Arabiyah Li al-Dirasat al-Lughawiyah.

Nasir, A. (2014). Pembelajaran Bahasa Arab untuk Calon Tenaga Kerja Indonesia (CTKI) ke Timur Tengah (Studi Kasus di PT. Mutiara Bahari Alamria Jatirangon, Jati Sampurna, Bekasi, Jawa Barat. UIN Sunan Kalijaga Yogyakarta.

R, F. S. (2006). Pendidikan Bahasa Arab (Antara Ekskulusif dan Inklusifisme). Jurnal Al'arabiyah, 2(2), 49-71.

Razak, N. S. Abd. (2018, July 3). Pembelajaran Bahasa Arab di UPNM [Personal communication].

Richards, J. C. (2008). Curriculum Development in Language Teaching. Cambridge University Press.

Robinson, P. (1991). ESP Today: A Practitioner's Guide. Prentice Hall.

Sabri, M. (3 Juli). Pembelajaran Bahasa Arab di IIUM [Personal communication].

Sahrir, M. S., Nasir, M. S., \& Yahaya, M. F. B. (2013). Pembelajaran Bahasa Arab Untuk Tujuan Ibadah Sebagai Satu Keperluan Bagi Masyarakat Awam. Malaysia International Conference on Foreign Languages (MICFL), 1.

Tu'aimah, R. A. (1989a). Al-Marja' fi Manahiji Ta'lim al-Lughah al-'Arabiyah li al-Natiqin bi Lughatin Ukhra. Dar al-Fikr al-'Arabi.

Tu'aimah, R. A. (1989b). Ta'lim al- 'Arabiyah li Ghair al-Nathiqina Biha,. ISESCO.

Tuesday, O. (2011). Foreign Language for Specific Purposes and Sustainable Human Development in Africa. Research Journal of International Studies, 19.

Umar, L. bin. (1999). Pengajaran dan Pembelajaran Bahasa Arab Untuk Tujuan-tujuan Khusus: Analisis Keperluan Di Malaysia. Universiti Malaya.

Wahab, M. A. (2007). Tantangan dan Prospek Pendidikan Bahasa Arab di Indonesia. Jurnal Afaq Arabiyyah, 2(1), 1-18.

Wati, A. T. (2012). Pengembangan Model Bahasa Arab untuk Mahasiswa Hubungan Internasional di Pusat Bahasa Universitas Muhammadiyah Yogyakarta," Tesis, Program Pascasarjana UIN Sunan Kalijaga Yogyakarta. UIN Sunan Kalijaga Yogyakarta. 